\title{
Cohalogenation of Alkenes with DMF: an Easy Vicinal Haloformyloxylation Reaction
}

\author{
Adriana V. A. de Souza, Gabriela F. Mendonça, Rafael B. Bernini and Marcio C. S. de Mattos* \\ Instituto de Química, Universidade Federal do Rio de Janeiro, CP 68545, \\ 21945-970 Rio de Janeiro-RJ, Brazil
}

\begin{abstract}
A reação de alquenos com o ácido tricloro-isocianúrico ou $N$-bromo-sacarina ou $\mathrm{I}_{2} / \mathrm{Fe}_{2}\left(\mathrm{SO}_{4}\right)_{3}$ na presença de DMF, seguida de tratamento em meio aquoso, leva à formação dos respectivos $\beta$-halo-formatos com alta regio- e estereosseletividade.

The reaction of alkenes with trichloroisocyanuric acid or $N$-bromosaccharin or $\mathrm{I}_{2} / \mathrm{Fe}_{2}\left(\mathrm{SO}_{4}\right)_{3}$ in the presence of DMF followed by aqueous work-up led to the corresponding $\beta$-haloformate in high regio- and stereoselectivity.
\end{abstract}

Keywords: addition reaction, alkenes, halogenation, esters, $\beta$-haloformyloxylation

\section{Introduction}

The vicinal functionalization of alkenes is an important process in synthetic organic chemistry and several methodologies are described in the literature. ${ }^{1}$ Among them, the so-called "cohalogenation" (halogenation of an alkene in the presence of a nucleophilic solvent) is an attractive tool to produce vicinal halo-functionalized compounds regioselectively, which are useful intermediates for diverse organic transformations. ${ }^{2}$ A proposed mechanism goes through formation of a halonium ion intermediate followed by ring opening promoted by the nucleophilic solvent. ${ }^{2}$ Thus, DMF can act as a nucleophile in the cohalogenation reaction $^{3}$ and so the halonium ion intermediate can be attacked by the oxygen of DMF to produce an iminium ion, which upon hydrolysis gives a vicinal haloformate ${ }^{4}$ (Scheme 1). In spite of its synthetic potential, this reaction has received little attention, being the vicinal haloformyloxylation of alkenes achieved using $\mathrm{DMF} / \mathrm{HCl}$ and an oxidizing agent ${ }^{4}$ or DMF / $N$-halosuccinimides. ${ }^{5-7}$

Alternative sources of electrophilic halogen species (halenium ions) are of great interest from both mechanistic and green synthesis points of view. ${ }^{8}$ Trichloroisocyanuric acid (TCCA, Figure 1) is a stable and inexpensive solid frequently found in a large number of commercial products for swimming pool disinfection. ${ }^{9,10} \mathrm{~N}$-bromosaccharin (NBSac, Figure 1) is a stable solid, easily prepared from saccharin ${ }^{11}$ and much more reative than its analogue

*e-mail:mmattos@iq.ufrj.br

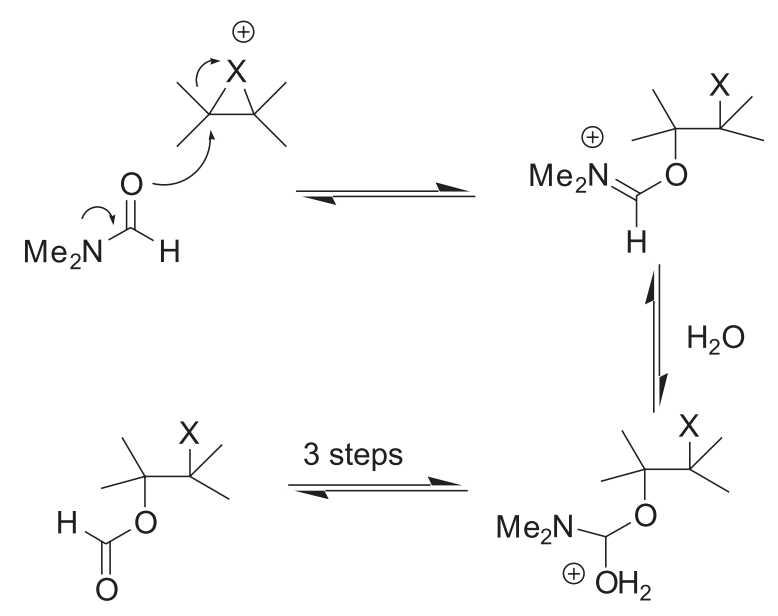

Scheme 1. Formation of $\beta$-haloformate from nucleophilic opening of an halonium ion by DMF followed by hydrolysis.

NBS. ${ }^{12}$ On the other hand, $\mathrm{I}_{2} / \mathrm{Fe}(\mathrm{III})$ salts are mild reagents for iodination of alkenes ${ }^{13}$ that avoid the utilization of oxidizing reagents and heavy-metal salts. ${ }^{14}$

During our investigation on cohalogenation reactions, ${ }^{15}$ we had shown that TCCA, NBSac, and $\mathrm{I}_{2} / \mathrm{Fe}_{2}\left(\mathrm{SO}_{4}\right)_{3}$ are efficient sources of electrophilic chlorine, ${ }^{16}$ bromine, ${ }^{17}$ and iodine ${ }^{18}$ species, respectively, that react with alkenes in the presence of diverse oxygenated solvents to give vicinal halofunctionalyzed structures (halohydrins, $\beta$-haloethers, and $\beta$-haloacetates).

Herein we communicate our results on the cohalogenation of alkenes with TCCA, NBSac, and $\mathrm{I}_{2} /$ $\mathrm{Fe}_{2}\left(\mathrm{SO}_{4}\right)_{3}$ in the presence of DMF to produce vicinal haloformates. 
<smiles>O=c1n(Cl)c(=O)n(Cl)c(=O)n1Cl</smiles>

TCCA<smiles>O=c1c2ccccc2sn1Br</smiles>

NBSac
Figure 1. Structures of TCCA and NBSac.

\section{Results and Discussion}

The reactions of representative alkenes (cyclohexene, styrene, $\alpha$-methylstyrene, and 1-octene) with the sources of electrophilic halogens in DMF afforded, after work up, the $\beta$-haloformates in $42-82 \%$ isolated yields, as shown in Table 1. The reactions were carried out stirring together the alkene with TCCA or NBSac or $\mathrm{I}_{2} / \mathrm{Fe}_{2}\left(\mathrm{SO}_{4}\right)_{3}$ in DMF for $1.5 \mathrm{~h}$ at room temperature, followed by addition of water and the

Table 1. Products obtained from Cohalogenation of alkenes with DMF

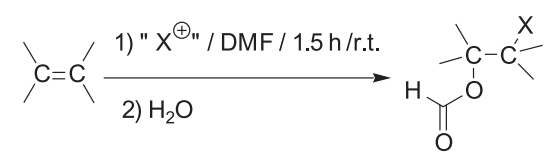

$$
\begin{aligned}
\mathrm{X} & =\mathrm{Cl}(\text { from TCCA) } \\
& =\mathrm{Br}(\text { from NBSac) } \\
& =\mathrm{I} \quad\left(\text { from } \mathrm{I}_{2} / \mathrm{Fe}_{2}\left(\mathrm{SO}_{4}\right)_{3}\right)
\end{aligned}
$$

\begin{tabular}{lll}
\hline Alkene & $\mathrm{X}$ & Yield / (\%) $)^{\mathrm{a}}$ \\
\hline & $\mathrm{Cl}$ & 69 \\
$\mathrm{OCHO}$ & $\mathrm{Br}$ & 82 \\
& $\mathrm{I}$ & 70
\end{tabular}

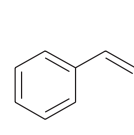<smiles>[X]CC(OC=O)c1ccccc1</smiles>

$\mathrm{Cl}$ $\mathrm{Br}$ I<smiles>CC(=Cc1ccccc1)c1ccccc1</smiles><smiles>[X]CC(C)(OC=O)c1ccccc1</smiles>

\section{$\mathrm{Cl}$} $\mathrm{Br}$ I

$\mathrm{Cl}$<smiles>[Li][Ca]C</smiles><smiles>[X]CC([Hg])OO</smiles>

$\mathrm{Br}$

a Isolated yield based on the alkene. ${ }^{b}$ Obtained predominantly ( $\left.c a .2: 1\right)$ with its regioisomer. ${ }^{c}$ Obtained predominantly $(c a .5: 1)$ with its regioisomer. products were analyzed by HRGC and characterized by spectroscopic methods (Table 2).

The orientation in the reaction follows the Markovnikoff pattern, with the expected exception ${ }^{19}$ of the aliphatic monosubstituted 1-octene that afforded a regioisomeric mixture of $\beta$-haloformates in which the secondary formate predominated $(2-5: 1)$. The process is also stereoselective, with cyclohexene yielding exclusively the trans-isomer, as can be seen (Figure 2) by the high values of the coupling constants ${ }^{20}$ for adjacent hydrogens of the haloformates derived from cyclohexane.

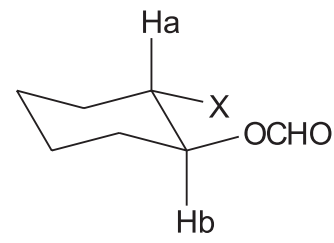

$$
\begin{aligned}
\mathrm{X}=\mathrm{Cl}: J_{\mathrm{HaHb}}=10.4 \mathrm{~Hz} \\
\mathrm{Br}: J_{\mathrm{HaHb}}=9.2 \mathrm{~Hz} \\
\mathrm{I}: J_{\mathrm{HaHb}}=9.0 \mathrm{~Hz}
\end{aligned}
$$

Figure 2. Coupling constants.

No diol, arising from Prèvost-Woodward reaction, ${ }^{21}$ was detected on the crude reaction mixture, but variable amounts of the corresponding halohydrins were observed, specifically in the cases of the iodoformate derived from $\alpha$-methylstyrene ( $16 \%$ yield from $\alpha$-methylstyrene) and the chloroformate derived from 1 -octene $(20 \%$ yield from 1 -octene), that could explain the low yields of $\beta$-haloformates obtained in these cases. The formation of the halohydrins could be rationalized by hydrolysis of the haloformate or its precursors during the work up. ${ }^{6}$ Alternatively, its formation by addition of water to the halonium ion seems to be improbable because, although we have used DMF without further purification and in an open flask, no loss of stereoselectivity in the reactions of cyclohexene (arising from small amounts of water ${ }^{22}$ ) was detected either.

\section{Conclusions}

In summary, we have developed a convenient route to vicinal haloformates from alkenes. The reaction conditions are mild, the work up process is very simple, the reagent employed are stable, cheap, and readily available and, furthermore, there is no need of special techniques and conditions.

\section{Experimental}

General

NBSac was prepared from saccharin, $\mathrm{KBr}$ and oxone ${ }^{\circledR}$, as early described..$^{11}$ Trichloroisocyanuric acid 
Table 2. Selected analytical data for products obtained

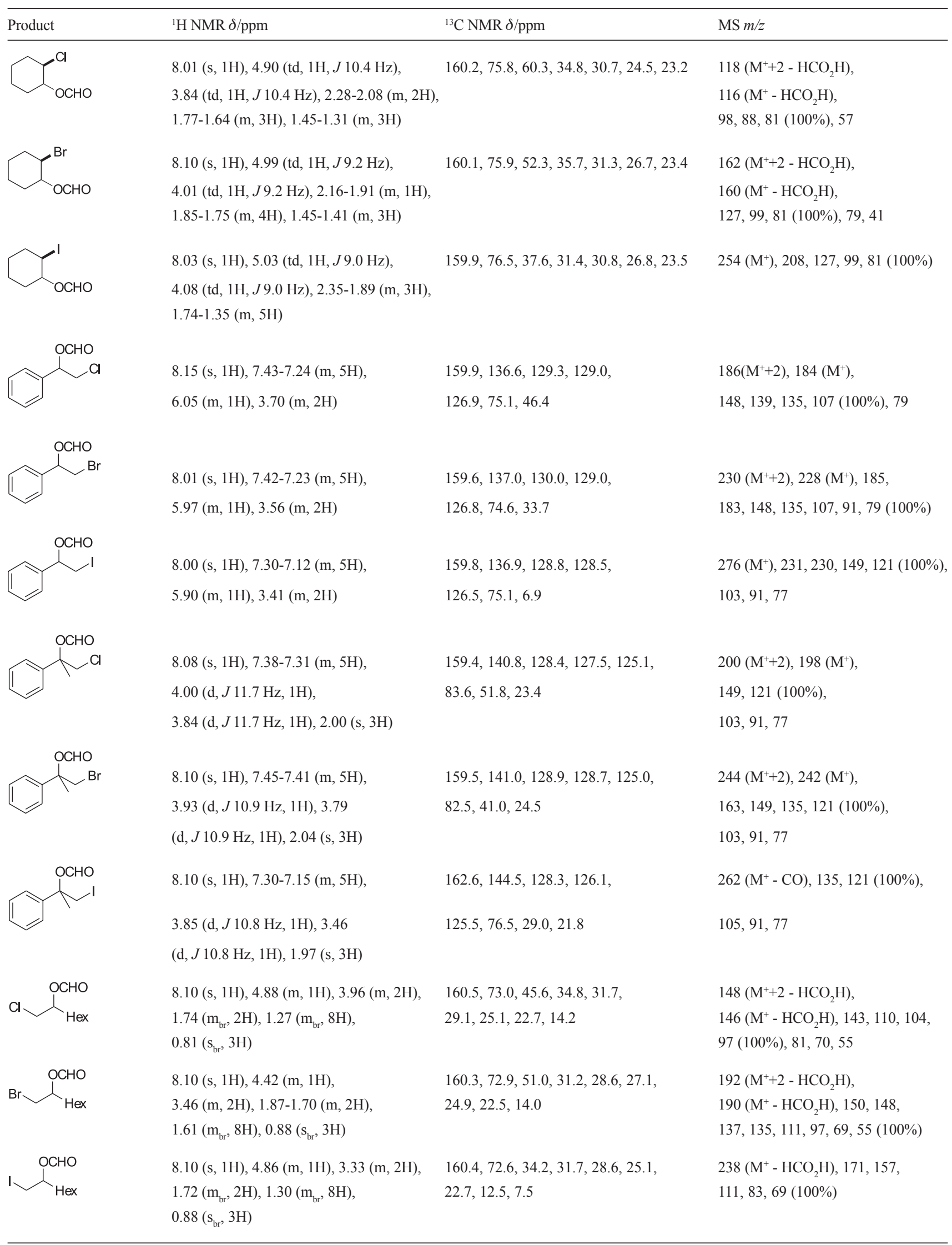


(commercial grade, 98\%), and other chemicals and solvents were used as received. The ${ }^{1} \mathrm{H}$ and ${ }^{13} \mathrm{C}$ NMR spectra were recorded on a Bruker AC-200 $(200 \mathrm{MHz}$ and $50 \mathrm{MHz}$, respectively) spectrometer in $\mathrm{CDCl}_{3}$ solution with TMS as internal standard. Highresolution GC was performed on a HP-5890-II gas chromatograph with FID using a $30 \mathrm{~m}$ (length), $0.25 \mathrm{~mm}$ (ID), and $25 \mu \mathrm{m}$ (phase thickness) RTX-5 capillary column and $\mathrm{H}_{2}$ (flow rate $50 \mathrm{~cm} \mathrm{~s}^{-1}$ ) as carrier gas (split: 1:10). Mass spectra were obtained on a Hewlett-Packard HP 5896-A HRGC-MS using electron impact $(70 \mathrm{eV})$.

\section{Preparation of $\beta$-chloroformates}

To a stirred solution of the alkene $(5 \mathrm{mmol})$ in DMF $\left(50 \mathrm{~cm}^{3}\right)$, TCCA $(2.5 \mathrm{mmol})$ was added at room temperature in small portions. After $1.5 \mathrm{~h}$, water $\left(10 \mathrm{~cm}^{3}\right)$ was added and the solution was extracted with $\mathrm{CH}_{2} \mathrm{Cl}_{2}$ $\left(20 \mathrm{~cm}^{3}\right)$. The organic layer was washed with satd $\mathrm{NaHSO}_{3}$, water and then dried (anhyd $\mathrm{Na}_{2} \mathrm{SO}_{4}$ ). After rotaevaporation of the solvent, the product was purified by radial chromatography on a Chromatotron ${ }^{\circledR}$. Spectral data of the products are shown in Table 2.

\section{Preparation of $\beta$-bromoformates}

Same as above, NBSac $(7.5 \mathrm{mmol})$ used instead of TCCA.

\section{Preparation of $\beta$-iodomoformates}

Same as above, $\mathrm{I}_{2}(7.5 \mathrm{mmol})$ and $\mathrm{Fe}_{2}\left(\mathrm{SO}_{4}\right)_{3}(6.0$ $\mathrm{mmol}$ ) used instead of TCCA.

\section{Acknowledgments}

A.V.A.S. and R.B.B. thank PIBIC-UFRJ; G.F.M. and M.C.S.M. thank CNPq.

\section{References}

1. Recent examples: Singh, S.; Singh, B.; Ind. Eng. Chem. Res. 2007, 46, 983; Taber, D. F.; Liang, J.-I.; J. Org. Chem. 2007, 72, 431; Minakata, S.; Yoneda, Y.; Oderaotoshi, Y.; Komatsu, M.; Org. Lett. 2006, 8, 967; Yeung, Y.-Y.; Gao, X.; Corey, E. J.; J. Am. Chem. Soc. 2006, 128, 9644; Urankar, D.; Rutar, I.; Modec, B.; Dolenc, D.; Eur. J. Org. Chem. 2005, 2349; Muñiz, K.; New J. Chem. 2005, 29, 1371; Pan, Z. L.; Liu, X. Y.; Liu, W. M.; Liang, Y. M.; Synthesis 2005, 437.

2. Rodriguez, J.; Dulcere, J.-P.; Synthesis 1993, 1177; Sanseverino, A. M.; da Silva, F. M.; Jones Jr., J.; de Mattos, M. C. S.; Quim. Nova 2001, 24, 637; da Silva, F. M.; Jones Jr., J.; de Mattos, M. C. S.; Curr. Org. Synth. 2005, 2, 393.
3. De Roocker, A.; De Radzitzki, P.; Bull. Soc. Chim. Belges 1970, 79, 531; Lasne, M. C.; Masson, S.; Thuillier, A.; Bull. Soc. Chim. Fr. 1973, 1751.

4. Kim, J. N.; Kim, H. R.; Ryu, E. K.; Synth. Commun. 1992, 22, 2521; Kim, H. R.; Kim, J. N.; Park, H. J.; Ryu, E. K.; Bull. Korean Chem. Soc. 1997, 18, 110.

5. NCS: Micev, I.; Christova, N.; Panajotova, B.; Jovtscheff, A.; Chem. Ber. 1973, 106, 606.

6. NBS: Dalton, D. R.; Smith Jr., R. C.; Jones, D. G.; Tetrahedron 1970, 26, 575.

7. NIS: Hamm, S.; Hennig, L.; Findeisen, M.; Müller, D.; Welzel, P.; Tetrahedron 2000, 56, 1345.

8. Almeida, L. S.; Esteves, P. M.; de Mattos, M. C. S.; Synthesis 2006, 221; Moghaddan, F. M.; Boeini, H. Z.; Synlett 2005, 1612; Filimonov, V. D.; Krasnokutskaya, E. A.; Lesina, Y. A.; Russ. J. Org. Chem. 2003, 39, 875; Sanseverino, A. M.; de Mattos, M. C. S.; Synthesis 1998, 1584.

9. Hiegel, G. A.; Nalbandy, M.; Synth. Commun. 1992, 22, 1589; Wengert, M.; Sanseverino, A. M.; de Mattos, M. C. S.; J. Braz. Chem. Soc. 2002, 13, 700.

10. For reviews on the utilization of TCCA in organic synthesis see: Tilstam, U.; Weinmann, H.; Org. Process Res. Dev. 2002, 6, 384; Barros, J. C.; Synlett 2005, 2115; Kolvani, E.; GhorbaniChoghamarani, A.; Salehi, P.; Shirini, F.; Zolfigol, M. A.; J. Iran. Chem. Soc. 2007, 4, 126.

11. de Souza, S. P. L.; da Silva, J. F. M.; de Mattos, M. C. S.; Synth. Commun. 2003, 33, 935.

12. For a review on the utilization of NBSac in organic synthesis see: de Souza, S. P. L.; da Silva, J. F. M.; de Mattos, M. C. S.; Quim. Nova 2006, 29, 1061.

13. de Mattos, M. C. S.; Sanseverino, A. M.; J. Chem. Res. (S) 1994, 440; Sanseverino, A. M.; da Silva, F. M.; Jones Jr., J.; de Mattos, M. C. S.; J. Braz. Chem. Soc. 2000, 11, 381.

14. For reviews on the utilization of $\mathrm{I}_{2}$ in organic synthesis see: Banerjee, A. K.; Vera, W.; Mora, H.; Laya, M. S.; Bedoya, L.; Cabrera, E. V.; J. Sci. Ind. Res. 2006, 65, 299; Togo, H.; Iida, S.; Synlett 2006, 2159.

15. For our recent works on cohalogenation reactions see: Almeida, L. S.; Esteves, P. M.; de Mattos, M. C. S.; Synlett 2007, 1687; Tozetti, S. D. F.; de Almeida, L. S.; Esteves, P. M.; de Mattos, M. C. S.; J. Braz. Chem. Soc. 2007, 18, 675; Villegas, R. A. S.; Santo Jr., J. L. E.; de Mattos, M. C. S.; de Aguiar, M. R. M. P.; Guarino, A. W. S.; Catal. Commun. 2007, 8, 97; de Almeida, L. S.; Esteves, P. M.; de Mattos, M. C. S.; Synlett 2006, 1515; de Mattos, M. C. S.; Bernini, R. B.; Heterocycl. Commun. 2006, 12, 411.

16. Mendonça, G. F.; Sanseverino, A. M.; de Mattos, M. C. S.; Synthesis 2003, 45.

17. de Souza, S. P. L.; da Silva, J. F. M.; de Mattos, M. C. S.; J. Braz. Chem. Soc. 2003, 14, 832.

18. de Mattos, M. C. S.; Sanseverino, A. M.; J. Chem. Res. 2004, 638. 
19. Sanseverino, A. M.; de Mattos, M. C. S.; Synth. Commun. 1998 , 28, 559; Villegas, R. A. S.; de Aguiar, M.R. M. P.; de Mattos, M. C. S.; Guarino, A. W. S.; Barbosa, L. M.; Assumpção, L. C. F. N.; J. Braz. Chem. Soc. 2004, 15, 150.

20. Lambert, J. B.; Shurvell, H. F.; Lightner, D. A.; Cooks, R.G.; Organic Structural Spectroscopy, Prentice Hall: New Jersey, 1998, p. 73.
21. Prévost, C.; Comp. Rend. Acad. Sci. 1933, 196, 1129; Woodward, R. B.; Brutcher Jr., V. R.; J. Am. Chem. Soc. 1958, 80, 209.

22. Campi, E. M.; Deacon, G. B.; Edwards, G. L.; Fitzroy, M. F.; Giunta, N.; Jackson, W. R.; Trainor, R.; J. Chem. Soc. Chem. Commun. 1989, 407. 